\title{
SOBREVIVÊNCIA E CRESCIMENTO INICIAL EM CAMPO DE ESPÉCIES FLORESTAIS NATIVAS DO BRASIL CENTRAL INDICADAS PARA SISTEMAS SILVIPASTORIS ${ }^{1}$
}

\begin{abstract}
Alex Melotto ${ }^{2}$, Maria Luiza Nicodemo $^{3}$, Ricardo Anghinoni Bocchese ${ }^{4}$, Valdemir Antônio Laura ${ }^{5}$, Miguel Marques Gontijo Neto ${ }^{6}$, Delano Dias Schleder ${ }^{4}$, Arnildo Pott ${ }^{5}$ e Vanderley Porfírio da Silva ${ }^{7}$

RESUMO - Objetivou-se, neste estudo, avaliar o índice de sobrevivência e o crescimento inicial de 11 espécies arbóreas nativas do Brasil central, plantadas diretamente em pastagem de Brachiaria brizantha cv. Marandu, em Campo Grande, MS. O solo foi classificado como Latossolo Vermelho, argiloso e distrófico, onde foi implantado um arboreto com 16 parcelas compostas, cada uma, por um indivíduo das 11 espécies selecionadas, em blocos casualizados (DBC) com quatro repetições. Os espaçamentos em campo foram de 10,0 x 4,0 m. Houve diferenças $(\mathrm{P}=0,05)$ entre as médias de sobrevivência das espécies estudadas, indicando influência do estágio sucessional da espécie. Os maiores índices foram de ocorrência nas seguintes espécies: ipê (Tabebuia impetiginosa), caroba (Jacaranda decurrens) e da aroeira (Myracrodruon urundeuva). As mais altas taxas de crescimento relativo nos 12 meses avaliados foram alcançadas por chico-magro (Guazuma ulmifolia), caroba (J. cuspidifolia) e canafístula (Peltophorum dubium). Houve diferença estatística $(\mathrm{P}=0,05)$ entre o crescimento das espécies de estágios sucessionais iniciais (pioneiras) e as de estádios tardios, e tais diferenças acentuaram-se com a idade e com a estação chuvosa. Três espécies que obtiveram as melhores combinações dos acréscimos em altura, diâmetro do colo e sobrevivência foram aptas para o cultivo em pastagens na região dos Cerrados: chicomagro (G. ulmifolia), caroba (J. cuspidifolias) e canafístula (P. dubium), sendo todas três de estágios sucessionais iniciais.
\end{abstract}

Palavras-chave: Arborização de pastagens, sistema silvipastoril e árvores do Cerrado.

\section{SURVIVAL AND INITIAL GROWING OF NATIVE TREE SEEDLINGS IN PASTURES OF CENTRAL BRAZIL}

\begin{abstract}
This work aimed to evaluate the rate of survival and the initial development of eleven native tree species established in existing pastures of Brachiaria brizantha at the Beef Cattle Center (Campo Grande, $M S)$. The soil is a dystrophic clay Dark-Red Latosoil. The seedlings were planted in 16 rows, with $10 \mathrm{~m}$ between rows and $4 \mathrm{~m}$ between plants in a row. It was used a completely randomized design with four replicates. Each row contained at least one seedling of all the trees evaluated. A repeat was composed of four rows. The Tukey test $(P=0,05)$ showed significant differences between the survival means, indicating that the seedling container and ecological succession groups (pioneer, early secondary, late secondary and climax) affected the results. The highest survival rates were found for the ipê (Tabebuia impetiginosa), caroba (Jacaranda cuspidifolia) and aroeira (Myracrodruon urundeuva). The highest rates of relative growth $(P=0,05)$ in 12 months were observed for chico-magro (Guazuma ulmifolia), caroba (J. cuspidifolia) and canafistula (Peltophorum dubium). The growth rates of the pioneer species were higher $(P=0,05)$ than the more advanced ecological
\end{abstract}

\footnotetext{
${ }^{1}$ Recebido em 19.02.2007 e aceito para publicação em 24.04.2009.

${ }^{2}$ Programa de Pós-Graduaçãoem Biologia Vegetal da UniversidadeFederal de MatoGrossodoSul(UFMS).E-mail: <alexmelotto@ @otmail.com>. ${ }^{3}$ CentrodePesquisadePecuáriadoSudestedaEmpresaBrasileiradePesquisaAgropecuáriOa(EMBRAPA).E-mail: <minicodemo@cppse.embrapa.br>. ${ }^{4}$ Programa de Pós-Graduação em Meio Ambiente e Desenvolvimento Regional da UNIDERP. E-mail: <bocchese@ hotmail.com>.

${ }^{5}$ Centro de Pesquisa Gado de Corte da EMBRAPA. E-mail: <valdemir@cnpgc. embrapa.br>.

${ }^{6}$ Centro Nacional de Pesquisa de Milho e Sorgo da EMBRAPA. E-mail: <mgontijo@ cnpms.embrapa.br>.

${ }^{7}$ Centro Nacional de Pesquisa de Florestas daEMBRAPA. E-mail: <porfirio@ cnpf.embrapa.br>.
} 
groups in the successional scale (late secondary and climax). The differences increased over the time and during rainy season $(P=0,05)$. The results indicated the use of three species to be established in the existing pasture of the Cerrado (savannahs), considering the increments in height, stem diameter and survival rate: chico-magro (G. ulmifolia), caroba (J. decurrens) and canafistula (Peltophorum dubium). The three species belong to the initial successional group.

Keywords: Cattle, ecological succession and ecological groups.

\section{INTRODUÇÃO}

Dados do IBGE de 1997 demonstram que cerca de $30 \%$ dos estabelecimentos rurais do Estado de Mato Grosso do Sul apresentam renda monetária bruta negativa, o que pode ser um indício de que, entre outras causas, os atuais sistemas de uso das terras não estão assegurando a capacidade produtiva dos recursos existentes (SILVA, 2003).

Nos Sistemas silvipastoris, a biomassa das árvores contribui para melhorar a fertilidade do solo, aumentar a disponibilidade de nitrogênio $(\mathrm{N})$ para as forrageiras herbáceas e melhorar a qualidade da forragem, algumas vezes aumentando também sua produção (CARVALHO, 1998), além de poder gerar renda extra pela venda e, ou, uso de postes, mourões, lascas e madeira. Um aspecto positivo da exploração de madeira na propriedade pecuária é a possibilidade de que o usufruto ou o corte da madeira seja feito conforme a oportunidade da época e da rentabilidade da floresta, entre outros, de forma que a idade ótima de rotação, ou do desbaste, ou da talhadia, não seja necessariamente prédeterminado como na agricultura. Assim, os plantios florestais permitem flexibilidade no corte de modo a maximizar os lucros, agregando renda à área da propriedade rural (RODIGHERI, 1997).

O Centro-Oeste brasileiro apresenta grande potencial de aplicação de sistemas agroflorestais, e em especial de Sistemas silvipastoris. Há grandes áreas de criação extensiva de gado com suas pastagens degradadas, bacias leiteiras com problemas de forrageamento no inverno, possibilidade de aplicação de cercas vivas, banco de proteínas e árvores de sombra (DANIEL et al., 2000). Dada a superfície ocupada pela pecuária, os Sistemas Silvipastoris podem causar grandes impactos ao ambiente. Considerado pela FAO (1954) como o nível mais baixo de uso da terra por uma relação simples de custo/benefício, a produção animal em pastagens solteiras apresenta inconvenientes ecológicos, sociais e econômicos, que podem ser mitigados com a utilização de Sistemas silvipastoris com espécies arbóreas (BAGGIO e CARPANEZZI, 1988).

A escolha de árvores apropriadas para o estabelecimento de Sistemas Silvipastoris é fundamental para o sucesso desses sistemas. Melo e Zoby (2004) apontaram algumas características desejáveis nas espécies para arborização de pastagens, como compatibilidade ecológica com o local, ser perenifólia, apresentar crescimento rápido, ser resistente a ventos, propiciar alimento, fixar nitrogênio, possuir troncos altos e copa pouco densa, de modo a possibilitar a passagem de luz, permitindo, assim, o desenvolvimento da forrageira embaixo de sua copa. Com a utilização de espécies florestais e herbáceas adequadas, a arborização das pastagens pode aumentar a produção e a qualidade das forrageiras e melhorar o desempenho dos animais em ganho de peso, lactação, sanidade e reprodução. Isso se deve, entre outros, à melhoria do microclima oferecido aos animais domésticos e nativos e para as plantas, além da maior ciclagem de nutrientes pelas árvores, incrementando a produtividade da pecuária extensiva de forma ambiental e econômica (BAGGIO, 1998).

As espécies selecionadas devem simultaneamente cumprir o objetivo do plantio e as exigências ecológicas regionais, garantindo, assim, retornos econômicos e ambientais satisfatórios.

No Brasil, a adoção de Sistemas Silvipastoris ainda depende de muito trabalho de divulgação das vantagens do sistema, bem como estudos sobre a adaptação de espécies a diferentes condições climáticas e de solo, visando identificar espécies alternativas às exóticas mais frequentemente utilizadas, como a grevílea e o eucalipto (BAGGIO e CARPANEZZI, 1998; CARVALHO et al., 2002). 
Além das espécies a serem utilizadas, a definição de que sistema de plantio deve ser empregado também tem suscitado discussões. O sistema de plantações mistas compostas de árvores nativas parece ser o mais adequado para atender aos objetivos propostos, por manterem, embora parcialmente, os processos que caracterizam a eficiência de conservação ambiental dos sistemas florestais naturais. Apresenta, também, maior amplitude de opções para o uso múltiplo da floresta (KAGEYAMA e CASTRO, 1989).

Neste trabalho, objetivou-se avaliar a sobrevivência e o crescimento inicial de 11 espécies arbóreas nativas do Brasil central, em um SSP com Brachiaria brizantha cv. Marandu.

\section{MATERIAL E MÉTODOS}

Este experimento foi conduzido na área experimental da Embrapa Gado de Corte, situada no Município de Campo Grande, M,S entre as coordenadas geográficas $20^{\circ} 26^{\prime} 39,61^{\prime \prime}$ S e $54^{\circ} 43^{\prime} 20,17^{\prime \prime}$ 'W. A área total do ensaio é de $6.400 \mathrm{~m}^{2}$ formada por pastagem de Brachiaria brizantha $\mathrm{cv}$. Marandu, com aproximadamente 12 anos de implantação. No local, teve a presença de gado bovino até três meses antes da implantação desse capim.

O solo no local.de realização deste trabalho foi
Latossolo Vermelho argiloso e distrófico. O clima pode foi classificado como tropical úmido (Aw), segundo Köppen, com estação chuvosa no verão e seca no inverno. A precipitação pluvial média anual foi em torno de 1.500 $\mathrm{mm}$, e as menores precipitações ocorreram nos meses de junho, julho e agosto.

Foram avaliadas 11 espécies florestais nesse experimento, as quais se encontram listadas na Tabela 1. A seleção das espécies foi baseada em seu potencial econômico, principalmente no que se refere a produção de madeira de qualidade e subprodutos e o valor ecológico na proteção do solo, abrigo para fauna nativa e se era exótica ou nativa. Dessa forma, procuraramse utilizar espécies com a maior multiplicidade de usos, baseando-se nas informações de Pott (1993). Todas as mudas utilizadas no experimento provieram de viveiros comerciais do Estado de Mato Grosso do Sul, embaladas em sacos de propileno ou tubetes, de acordo com a disponibilidade no comércio local.

Implantou-se um bosque com 16 parcelas, compostas cada uma por 11 mudas, sendo uma de cada espécie selecionada, em um delineamento estatístico de blocos casualizados (DBC), com quatro repetições de quatro parcelas, totalizando 176 mudas. Os espaçamentos de plantio foram de 4,0 m entre plantas e 10,0 m entre linhas.

Tabela 1 - Espécies arbóreas avaliadas: sobrevivência e desenvolvimento inicial em um sistema silvipastoril em Campo Grande, MS

Table 1 - Wood species evaluated as to survival rate and initial growth in a Sylvopastoral system in Campo Grande, MS

\begin{tabular}{|c|c|c|c|c|}
\hline Nome Popular & Nome Científico & Família & Sucessional & Bioma/Ecossistema \\
\hline Caroba & Jacaranda cuspidifolia Cham. & Bignoniaceae & Inicial & Cerradão \\
\hline Chico-magro & Guazuma ulmifolia Lamb. & Sterculiaceae & Inicial & $\begin{array}{l}\text { Cerradão, Floresta estacional } \\
\text { e mata ciliar }\end{array}$ \\
\hline Canafístula & Peltophorum dubium Taub. & $\begin{array}{l}\text { Fabaceae - } \\
\text { Caesalpiniaceae }\end{array}$ & Inicial & $\begin{array}{l}\text { Floresta estacional, floresta } \\
\text { mesófila e mata ciliar }\end{array}$ \\
\hline Copaíba & Copaifera langsdorffii Desf. & $\begin{array}{l}\text { Fabaceae - } \\
\text { Caesalpiniaceae }\end{array}$ & Tardia & $\begin{array}{l}\text { Floresta estacional, Cerradão } \\
\text { e mata ciliar }\end{array}$ \\
\hline Ipê-roxo & Tabebuia impetiginosa Stanley & Bignoniaceae & Tardia & Floresta estacional, cerradão \\
\hline Amendoim-bravo & Pterogyne nitens Tul. & $\begin{array}{l}\text { Fabaceae - } \\
\text { Caesalpiniaceae }\end{array}$ & Inicial & Floresta estacional \\
\hline Angico & $\begin{array}{l}\text { Anadenathera colubrina } \\
\text { Brenan }\end{array}$ & $\begin{array}{l}\text { Fabaceae- } \\
\text { Mimosaceae }\end{array}$ & Inicial & Floresta estacional, cerradão \\
\hline Guanandi & $\begin{array}{l}\text { Calophyllum brasilienses } \\
\text { Cambess. }\end{array}$ & Clusiaceae & Tardia & Mata ciliar, mata inundável \\
\hline Aroeira & $\begin{array}{l}\text { Myracrodruon urundeuva } \\
\text { Fr. AII. }\end{array}$ & Anacardiaceae & Tardia & Floresta estacional, cerradão \\
\hline Cedro & Cedrella fissilis Vell. & Meliaceae & Inicial & $\begin{array}{l}\text { Floresta estacional, floresta } \\
\text { mesófila }\end{array}$ \\
\hline Cumbaru & Dipteryx alata Vogel & Fabaceae - Faboidae & Tardia & cerradão \\
\hline
\end{tabular}


Dois meses antes do plantio foi feita a calagem, aplicando-se na cova de aproximadamente $30 \times 60 \mathrm{~cm}$ (largura x profundidade) cerca de $30 \mathrm{~g}$ de calcário dolomítico, conforme necessidade segundo a amostragem do solo. Nesse momento, também foi realizada a adubação química nas covas, através da incorporação de 100 g/cova de NPK 8-28-16 + Zn e B com o solo retirado da cova, seguindo-se indicações de plantios florestais comerciais. Essa mesma dosagem de adubação foi repetida um ano após a realização da primeira.

A fim de eliminar a Brachiaria brizantha nas proximidades da cova de plantios das mudas das espécies florestais, foi aplicado um mês antes do plantio o herbicida comercial Glifosato ${ }^{\circledR}(20 \mathrm{ml} / \mathrm{lt})$, num raio de $50 \mathrm{~cm}$. Esse procedimento foi repetido a cada 13 semanas, porém com um raio de 1,0 m devido à ineficiência na capina química observada no raio utilizado na primeira aplicação.

As mudas foram transplantadas no campo em 23/ 12/2004 e irrigadas semanalmente de abril a junho/2005. Durante todo o período experimental, realizou-se controle de formigas-cortadeiras, utilizando cerca de $10 \mathrm{~g}$ de isca granulada Mirex - $\mathrm{S}^{\circledR}$ à base de sulfluramida por $\mathrm{m}^{2}$ de formigueiro. Setenta dias após o plantio foi avaliado o índice de sobrevivência. As avaliações iniciais $\left(\mathrm{T}_{0}\right)$ de altura e diâmetro do colo das mudas foram feitas 120 dias depois do plantio; a partir dessa data a cada 17 semanas, foram repetidas as mesmas medições durante o período de um ano.

As diferenças de altura e diâmetro do colo por data de coleta subsidiaram os cálculos da Taxa de Crescimento Relativo (TCR) das mudas pela fórmula descrita por Benincasa (2003). As médias de sobrevivência de cada espécie foram comparadas entre si, pelo teste de Tukey a 5\% de significância, e as médias de crescimento em diâmetro e colo para iniciais e tardias foram comparadas por análise de variância (ANOVA).

\section{RESULTADOS E DISCUSSÃO}

\subsection{Sobrevivência}

Houve diferenças significativas na taxa de sobrevivência das espécies florestais avaliadas $(\mathrm{P}=0,05)$, indicando diferentes potenciais de adaptação e índices de sobrevivência variáveis no ambiente onde foram implantadas (Tabela 2). Tal fato evidencia a existência da relação sítio de plantio x espécie, com diferentes respostas da espécie ao local de plantio, a exemplo do que foi relatado por Vieira et al. (2003), em que as espécies com 21 meses de idade apresentaram índices de sobrevivência entre $5 \%$ e $94 \%$ na ocorrência de seis geadas durante 11 dias, em um sistema agrossilvicultural em Florianópolis, SC.

As espécies caroba ( $J$. decurrens), ipê ( $T$. impetiginiosa) e aroeira (Myracrodruon urundeuva) apresentaram os maiores índices de sobrevivência, respectivamente $100 \%, 100 \%$ e $93,75 \%$. Tal fato pode ser devido ao tipo e tamanho dos recipientes, em que as mudas se encontravam contidas. Essas três espécies foram produzidas em sacos plásticos com volume mínimo de $200 \mathrm{~cm}^{3}$, enquanto as demais estavam embaladas em tubetes de $50 \mathrm{~cm}^{3}$. O apropriado dimensionamento do volume, altura e diâmetro do recipiente variam conforme a espécie, ressaltando-se que as plântulas de folhosas tropicais tendem a requerer recipientes maiores do que os tubetes de $50 \mathrm{~cm}^{3}$ usados para Pinus e Eucalyptus. A restrição do crescimento do sistema radicular, proporcionado pelo menor volume do recipiente, pode promover o desequilíbrio na razão entre raízes e parte aérea, alterando as respostas fisiológicas da planta, repercutindo na qualidade da muda e também na planta adulta, muitos anos após o plantio (REIS et al., 1989; NEVES, 2005).

Tabela 2 - Índice de sobrevivência aos 30 dias de 11 espécies nativas do Cerrado plantadas diretamente em pastagem de Brachiaria brizantha cv. Marandu

Table 2-30-day planting survival rate of 11 Cerrado native species directly planted in Brachiaria brizantha $\mathrm{cv}$. Marandu pasture

\begin{tabular}{lc}
\hline Espécie & Sobrevivência $(\%)^{*}$ \\
\hline Tabebuia impetiginosa & $100,00^{\mathrm{a}}$ \\
Jacaranda cuspidifolia & $100,00^{\mathrm{a}}$ \\
Myracrodruon urundeuva $^{\mathrm{a}}$ & $93,75^{\mathrm{a}}$ \\
Guazuma ulmifolia $^{\mathrm{ab}}$ & $75,00^{\mathrm{ab}}$ \\
Peltophorum dubium & $68,75^{\mathrm{ab}}$ \\
Anadenanthera colubrina & $56,25^{\mathrm{abc}}$ \\
Calophyllum alata & $56,25^{\mathrm{abc}}$ \\
Pterogyne nitens & $43,75^{\mathrm{abc}}$ \\
Cedrella fissilis $_{\text {Copaifera langsdorffii }}$ & $31,25^{\mathrm{abc}}$ \\
\hline
\end{tabular}

*-Letras diferentes sobrescritas indicam valores estatisticamente diferentes entre as médias, pelo teste de Tukey a 5\%). 
Houve influência do ambiente na adaptação e, consequentemente, na sobrevivência das mudas, pois os três maiores e os três menores índices são pertencentes a espécies nativas do Cerradão (condição ecológica natural da área de estudo) e Floresta Decidual/ Semidecidual (LORENZI, 1998), respectivamente, o que indica a importância da escolha de espécies nativas adaptadas às condições edafoclimáticas locais ou originárias de bioma/ecossistema encontrado no local de implantação do Sistema.

\subsection{Crescimento}

Todas as espécies apresentaram taxas de crescimento relativo (TCR) positivas nos períodos avaliados, e após 240 e 360 dias de plantio esses valores foram mais expressivos, com exceção da Canafístula ( $P$. dubium) (Tabela 3 ).

O maior acréscimo no crescimento em altura e diâmetro do colo foi observado 360 dias após o plantio (Tabela 4). A explicação para esse fato pode ser pela coincidência do início da estação chuvosa na região, que conferiu maiores índices pluviais, possibilitando maior crescimento em relação aos meses de inverno (abril a outubro) e de final das chuvas (janeiro a abril) (Figura 1).

Tabela 3 - Taxa de crescimento relativo (TCR, em cm/mês) em altura total (Ht, em cm), diâmetro do colo (DC, em cm) e número de indivíduos (n) por período de quatro meses e ao final de 12 meses de coleta de 11 espécies florestais nativas do Cerrado, plantadas em pastagem de Brachiaria brizantha cv. Marandu em Campo Grande, MS

Table 3 - Relative growth rate (RGR in cm/month) on total height (Ht in cm), stem diameter (DC in cm) and number of plants per period of four months and at the end of a 12 month-collection of 11 Cerrado native wood species, planted in pasture of Brachiaria brizantha cv. Marandu in the Embrapa Gado de Corte in Campo Grande, MS

\begin{tabular}{|c|c|c|c|c|c|c|c|c|c|c|c|c|}
\hline \multirow[t]{2}{*}{ Espécie } & \multicolumn{3}{|c|}{$26 / 04-15 / 8 / 05$} & \multicolumn{3}{|c|}{$15 / 08-20 / 12 / 05$} & \multicolumn{3}{|c|}{$20 / 12 / 05-11 / 4 / 06$} & \multicolumn{3}{|c|}{$\overline{\text { TOTAL-12 meses }}$} \\
\hline & $\mathrm{n}$ & $\mathrm{Ht}$ & DC & $\mathrm{n}$ & $\mathrm{Ht}$ & DC & $\mathrm{n}$ & $\mathrm{Ht}$ & DC & $\mathrm{n}$ & $\mathrm{Ht}$ & DC \\
\hline Amendoim & 5 & 0,21 & 0,011 & 3 & 7,98 & 0,193 & 5 & 0,65 & 0,014 & 5 & 3,15 & 0,083 \\
\hline Angico & 12 & 0,09 & 0,008 & 11 & 12,14 & 0,084 & 11 & 2,44 & 0,062 & 12 & 4,98 & 0,051 \\
\hline Aroeira & 15 & 0,05 & 0,046 & 15 & 3,99 & 0,134 & 15 & 1,98 & 0,063 & 15 & 2,01 & 0,081 \\
\hline Canafístula & 11 & 2,54 & 0,188 & 10 & 9,91 & 0,335 & 10 & $-2,01$ & $-0,02$ & 12 & 3,48 & 0,168 \\
\hline Cedro & 4 & 0,63 & 0,15 & 4 & 7 & 0,246 & 4 & 1,5 & 0,217 & 4 & 3,04 & 0,204 \\
\hline Copaíba & 7 & 0,36 & 0,024 & 3 & 6,58 & 0,114 & 3 & 0,75 & $-0,029$ & 3 & 2,57 & 0,036 \\
\hline Cumbaru & 9 & 0,28 & 0,027 & 9 & 3,73 & 0,087 & 8 & 2,25 & 0,091 & 9 & 2,09 & 0,068 \\
\hline Guanandi & 3 & 2,27 & 0,041 & 2 & 2,15 & 0,124 & 2 & 6,75 & 0,127 & 3 & 3,72 & 0,098 \\
\hline Ipê & 16 & 1,06 & 0,068 & 16 & 3,43 & 0,062 & 16 & 1,52 & 0,109 & 16 & 2,00 & 0,080 \\
\hline Caroba & 16 & 0,59 & 0,077 & 16 & 8,48 & 0,296 & 16 & 4,66 & 0,011 & 16 & 4,58 & 0,128 \\
\hline Chico-magro & 14 & 1,41 & 0,102 & 12 & 12,11 & 0,293 & 13 & 4,08 & 0,252 & 13 & 5,87 & 0,216 \\
\hline
\end{tabular}

Tabela 4 - Médias quadrimestrais de altura total (Ht, em cm) e diâmetro do colo (DC, em cm), de abril de 2005 a abril de 2006, de 11 espécies florestais nativas do Cerrado plantadas em pastagem de Brachiaria brizantha cv. Marandu em Campo, MS

Table 4 - Four-month means for height and stem diameter from April 2005 to April 20061 for the 11 Cerrado native wood species, planted in pasture of Brachiaria brizantha cv. Marandu in Campo Grande, MS

\begin{tabular}{|c|c|c|c|c|c|c|c|c|}
\hline \multirow[t]{2}{*}{ Espécie } & \multicolumn{2}{|c|}{$26 / 4 / 2005$} & \multicolumn{2}{|c|}{$15 / 8 / 2005$} & \multicolumn{2}{|c|}{$20 / 12 / 2005$} & \multicolumn{2}{|c|}{$11 / 4 / 2006$} \\
\hline & $\mathrm{Ht}$ & DC & $\mathrm{Ht}$ & $\mathrm{DC}$ & $\mathrm{Ht}$ & $\mathrm{DC}$ & $\mathrm{Ht}$ & DC \\
\hline Amendoin & 27,20 & 0,57 & 30,50 & 0,74 & 62,40 & 1,51 & 65,00 & 1,56 \\
\hline Angico & 36,33 & 0,45 & 37,82 & 0,48 & 86,36 & 0,81 & 96,14 & 1,06 \\
\hline Aroeira & 38,28 & 0,65 & 38,47 & 0,84 & 54,44 & 1,37 & 62,34 & 1,62 \\
\hline Canafístula & 44,50 & 0,89 & 54,65 & 1,65 & 94,30 & 2,99 & 86,25 & 2,91 \\
\hline Cedro & 22,50 & 0,93 & 25,00 & 1,53 & 53,00 & 2,51 & 59,00 & 3,38 \\
\hline Copaíba & 10,21 & 0,27 & 11,67 & 0,37 & 38,00 & 0,82 & 41,00 & 0,71 \\
\hline Cumbaru & 9,33 & 0,36 & 10,44 & 0,47 & 25,38 & 0,82 & 34,39 & 1,18 \\
\hline Guanandi & 49,67 & 0,64 & 58,75 & 0,80 & 67,33 & 1,30 & 94,33 & 1,81 \\
\hline Ipê & 84,22 & 1,10 & 88,47 & 1,37 & 102,19 & 1,62 & 108,25 & 2,06 \\
\hline Caroba & 52,75 & 1,17 & 55,13 & 1,48 & 89,06 & 2,66 & 107,69 & 2,70 \\
\hline Chico-magro & 51,00 & 0,73 & 56,63 & 1,13 & 105,08 & 2,31 & 121,38 & 3,31 \\
\hline
\end{tabular}




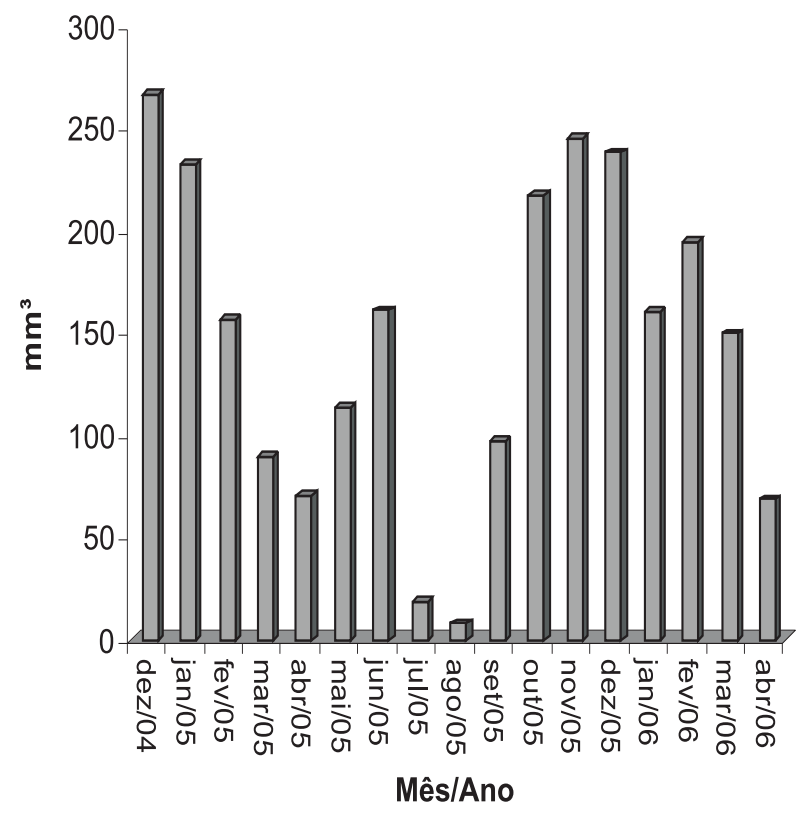

Figura 1 - Precipitação pluvial mensal entre os meses de dezembro de 2004 (dez./04) e abril de 2006 (abr./ 06), na Embrapa Gado de Corte, em Campo Grande, MS.

Figure 1 - Monthly rainfall rate between December 2004 and April 2006 at the Embrapa Gado de Corte, in Campo Grande, MS.

As oscilações no número de indivíduos (n) são justificadas pela entrada eventual, não desejada, de gado no experimento, causando redução inicial do número de indivíduos e uma posterior rebrota de alguns indivíduos. Isso promoveu uma TCR negativa da Canafístula (P. Dubium) no período de 20/12/2005 a 11/4/2006 (360 e 480 dias após o plantio, respectivamente). Em copaíba ( $C$. langsdorffii), a taxa negativa de incremento no diâmetro do colo pode ter ocorrido devido a uma irregularidade na forma do coleto das plantas.

As espécies que apresentaram maiores TCRs total em altura ( $\mathrm{cm} / \mathrm{cm} / \mathrm{mês})$ em ordem decrescente foram, respectivamente: chico-magro, angico (A. colubrina), caroba (J. cuspidifolia), guanandi (C. brasilienses) e a canafístula ( $P$. dubium). As maiores TCRs em diâmetro do colo foram observadas nas seguintes espécies: chicomagro (G. ulmifolia), cedro (C. fissilis), canafístula (P. dubium), caroba (J. decurrens) e o guanandi ( $C$. brasiliense) (Tabela 4$)$.

As plantas com maior Taxa de Crescimento Relativo foram as pertencentes ao grupo ecológico das pioneiras, sendo: Amendoim ( $P$. nittens), angico (A. colubrina), canafístula, ( $P$. dubium) cedro ( $C$. fissilis), caroba ( $J$. decurrens) e chico-magro (G. ulmifolia). Das espécies classificadas quanto ao grupo ecológico como tardias, tem-se o guanandi (C. brasiliensis), que teve o melhor desempenho. Houve diferença estatística $(\mathrm{P}=0,05)$ entre o crescimento das espécies de estágios sucessionais iniciais (pioneiras) e as de estádios avançados (tardias) (Tabela 5), e tais diferenças acentuaram-se com o passar do tempo e a chegada da estação chuvosa. Gonçalves et al. (1992a,b) verificaram que espécies dos grupos ecológicos iniciais, que possuíam sistema radicular mais desenvolvido e raízes finas em maior quantidade, apresentaram as maiores taxas de crescimento e absorveram mais nutrientes que as tardias, nas quais foi constatada a presença de raízes atrofiadas e espessas. Tal fato também foi obtido por Botelho et al. (1996), verificando que aos 27 meses o desenvolvimento das espécies iniciais quanto ao grupo ecológico foram mais acentuados.

Tabela 5 - Média e desvio-padrão (DP) das medidas de crescimento de espécies dos grupos sucessionais nos diferentes períodos de avaliação (ANOVA)

Table 5 - Mean and standard deviation of the growth measures for the different successional group species at different evaluation periods

\begin{tabular}{|c|c|c|c|c|}
\hline \multirow[b]{2}{*}{ Grupo } & \multicolumn{4}{|c|}{ Altura Total } \\
\hline & $26 / 4 / 2005$ & $15 / 8 / 2005$ & $20 / 12 / 2005$ & $11 / 4 / 2006$ \\
\hline Sucessional & Média/DP & Média/DP & Média/DP & Média/DP \\
\hline Iniciais & $42,08 \pm 14,97$ & $48,89 \pm 15,85$ & $88,43 \pm 20,96$ & $96,69 \pm 25,01$ \\
\hline \multirow[t]{3}{*}{ Tardias } & $35,27 \pm 28,96$ & $41,10 \pm 32,07$ & $57,84 \pm 31,77$ & $66,58 \pm 32,45$ \\
\hline & $P=0,352$ & $\mathrm{P}=0,365$ & $\mathrm{P}=0,001$ & $\mathrm{P}=0,003$ \\
\hline & \multicolumn{4}{|c|}{ Diâmetro do Colo } \\
\hline Iniciais & $0,74 \pm 0,30$ & $1,13 \pm 0,50$ & $2,10 \pm 0,90$ & $2,34 \pm 0,98$ \\
\hline \multirow[t]{2}{*}{ Tardias } & $0,65 \pm 0,34$ & $0,95 \pm 0,55$ & $1,41 \pm 0,61$ & $1,83 \pm 0,87$ \\
\hline & $\mathrm{P}=0,363$ & $\mathrm{P}=0,323$ & $\mathrm{P}=0,010$ & $\mathrm{P}=0,105$ \\
\hline
\end{tabular}

R. Árvore, Viçosa-MG, v.33, n.3, p.425-432, 2009 
O plantio das espécies nativas propiciou a diversificação da vegetação, que anteriormente era restrita a Poaceae.

\section{CONCLUSÕES}

As três espécies que obtiveram as melhores combinações dos acréscimos em altura, diâmetro do colo e sobrevivência, podem ser utilizadas em Sistemas Silvipastoris na região dos cerrados na região de Campo Grande: chico-magro (G. ulmifolia), caroba (J. decurrens) e canafístula ( $P$. dubium).

Para obter sucesso na implantação de um Sistema Silvipastoril na região de Cerrado de Campo Grande, MS, devem-se, preferencialmente, utilizar mudas de espécies pertencentes aos grupos ecológicos iniciais da sucessão, adequadas à região, respeitando, assim, suas condições ecofisiológicas e minimizando os prejuízos econômicos decorrentes de eventuais replantios.

\section{AGRADECIMENTOS}

À Fundect/MS e ao CNPq, pelo apoio financeiro e pelas bolsas; a toda a equipe da Embrapa Gado de Corte, em especial ao Sr. José Porfírio, pelo auxílio na manutenção do experimento; e ao Sr. Bernardino Bezerra, pela ajuda no delineamento experimental.

\section{REFERÊNCIAS}

BAGGIO, A. J.; CARPANEZZI, O. B. Alguns sistemas de arborização de pastagens. Boletim de Pesquisa Florestal, n.17, p.47-60, 1988.

BAGGIO, A. J. Seleção de espécies para formação de bosquetes de proteção em pastagens para a região do arenito Caiuá, no Paraná. Pesquisa em Andamento, n.61, p.1-5, 1998.

BENINCASA, M. M. P. Análise de crescimento de plantas (noções básicas). Jaboticabal: Funep, 2003. 41p.

BOTELlHO, S. A.; DAVIDE, A. C.; FARIA, J. M. R. Desenvolvimento inicial de seis espécies florestais nativas em dois sítios, na região sul de minas gerais. Cerne, v.2, n.1, p.4-13, 1996.
CARVALHO, M. M. Recuperação de pastagens degradadas em áreas de relevo acidentado. In: DIAS, L. E.; MELLO, J. W. V. (Eds.) Recuperação de áreas degradadas. Viçosa, MG: Universidade Federal de Viçosa; Sociedade Brasileira de Recuperação de Áreas Degradadas, 1998. p.149-162.

CARVALHO, M. M. et al. Estabelecimento de sistemas silvipastoris: ênfase em áreas montanhosas e solos de baixa fertilidade. Juiz de Fora: Embrapa Gado de Leite, 2002. 12p. (Circular Técnica, 68).

DANIEL, O.; PASSOS, C. A. M.; COUTO, L. Sistemas agroflorestais (silvipastoris e agrissilvipastoris) na região centro-Oeste do Brasil: potencialidades, estado atual da pesquisa e da adoção de tecnologia. In: CARVALHO, M. M.; ALVIM, M. J.; CARNEIRO, J. D. C. (Eds.). SIMPÓSIO INTERNACIONAL SISTEMAS AGROFLORESTAIS PECUÁRIOS NAAMÉRICADO SUL, 2000, Juiz de Fora. Anais... Juiz de Fora: Embrapa Gado de Leite, FAO, 2000. CD-ROM.

FAO. El maiz en la alimentación. Estudios sobre nutrición. Roma: 1954. 100p.

GONÇALVES, J. L. M. et al. Produção de biomassa e sistema radicular de espécies de diferentes estágios sucessionais. Revista do Instituto Florestal, v.4, p.363-367, 1992a. (Edição Especial).

GONÇALVES, J. L. M. et al. Capacidade de absorção e eficiência nutricional de algumas espécies arbóreas tropicais. Revista do Instituto Florestal, v.4, p.463-469, 1992 b. (Edição Especial).

KAGEYAMA, P. Y.; CASTRO, C. F. A. Sucessão secundária, estrutura genética e plantações de espécies arbóreas nativas. IPEF, n.41/42, p.83-93,1989.

LORENZI, H. Árvores Brasileiras: manual de identificação e cultivo de plantas arbóreas nativas do Brasil. 2.ed. Nova Odessa: Plantarum, 1998. v.1.367p.

MELO, J. T.; ZOBY, J. L. F. Espécies para arborização de pastagens. Planaltina: Embrapa-CPAC, 2004. 4p. (Circular Técnica, 113).

R. Árvore, Viçosa-MG, v.33, n.3, p.425-432, 2009 
NEVES, C. S. V. J. et al. Efeitos de substratos e recipientes utilizados na produção das mudas sobre a arquitetura do sistema radicular de árvores de cácianegra. Revista Árvore, v.29, n.6, p.897-905, 2005.

POTT, A. Árvores no sistema silvipastoril. In: SIMPÓSIO SOBREUSOSMÚLTIPLOSDELEGUMINOSAS ARBUSTIVAS EARBÓREAS, 1993, Nova Odessa. Anais... Nova Odessa: Alcêntra, 1993. p.95-129.

POTT, A.; POTT, V. J. Plantas Nativas potenciais para sistemas agroflorestais em Mato Grosso do Sul. In: SEMINÁRIO SISTEMAS AGROFLORESTAIS E DESENVOLVIMENTO SUSTEnTÁ VEL, 2003, Campo Grande. Anais... Campo Grande: Embrapa, 2003. CD-ROM.

REIS, G. G. et al. Crescimento de Eucalyptus camaldulensis, E. grandis e E. cloensiana sob diferentes níveis de restrição radicular. Revista Árvore, v.13, n.1, p.1-18, 1989.
RODIGHERI, H. R. Rentabilidade econômica comparativa entre plantios florestais e sistemas agroflorestais com erva-mate, eucalipto e pinus e as culturas do feijão, milho, soja e trigo. Colombo: Embrapa-CNPF, 1997. 36p. (Circular Técnica, 26).

SILVA, V. P. Sistemas silvipastoris em Mato Grosso do Sul - para que adotá-los? In: SEMINÁRIO SISTEMAS AGROFLORESTAIS E DESENVOLVIMENTO SUSTENTÁVEL, 2003, Campo Grande. Anais...Campo Grande: Embrapa, 2003. CD-ROM.

VIEIRA, R. R.; FEISTAUER, D.; PORFIRIO DA SILVA, V. Adaptação da espécies arbóreas nativas em um sistema Agrossilvicultural, submetidas a extremos climáticos de geada na região de Florianópolis. Revista Árvore, v.27, n.5, p.627-634, 2003. 